\title{
The physician and conflict of interest
}

\author{
Peter T Scardino and Suzanne J Farley
}

Conflict of interest is defined as the private, institutional or business interests of individual physicians that may be at odds with their responsibility to the wellbeing of their patients. Conflicts of this nature abound in the practice of urology.

Decisions that might be manipulated to the physician's advantage arise immediately upon interaction with a new patient. An unavoidable dilemma subject to personal bias is encapsulated by the question 'should my treatment recommendation be the surgical technique that I perform, or one delivered by another specialist?' Desire to retain control of patient management is a strong motivator. The development of brachytherapy and cryotherapy for prostate cancer was partially driven by urologists' desire for a nonsurgical treatment that permits them to remain involved in provision of care.

Physician involvement in the development of such techniques, as well as drugs and devices, inevitably raises issues of competing financial interest. These can generally be circumvented by physician-inventors excluding themselves from clinical trials of their innovations. While it may be acceptable for the inventor's expertise to be utilized to perform the first few procedures/tests on human subjects, guidelines recommend that they not be involved in collecting or analyzing data, or in giving detailed presentations of trial data.

Plato observed that no-one would take on the troubles of another without expecting recompense. Indeed, it is a central tenet of medical practice that physicians are paid for services rendered personally, but serious conflicts develop when physicians can derive monetary benefit through referring their patients to a service provider in which they, or those related to them, have a financial stake. Physician-owned specialty hospitals are an emerging phenomenon in the US at the heart of a serious dispute focused on conflicts of this nature.

Certain billing arrangements present opportunities for physicians to fraudulently gain financial advantage. One such arrangement in the US involves receiving a service on behalf of a

\section{The onus \\ is now on \\ physicians \\ to be aware \\ of their \\ obligations \\ under the law \\ and the serious \\ penalties \\ that can be \\ imposed for \\ breaking those \\ obligations}

PT Scardino is the

Editor-in-Chief

of Nature Clinical

Practice Urology,

Chairman of the

Department of

Urology at Sidney

Kimmel Center for

Prostate and Urologic

Cancers, and Alfred

$P$ Sloan Chair at

Memorial Sloan-

Kettering Cancer

Center. SJ Farley is

an Associate Editor,

Nature Clinical

Practice.

\section{Competing interests}

The authors declared

they have no competing

interests.

www.nature.com/clinicalpractice doi:10.1038/ncpuro0125 patient (e.g. from a pathology laboratory) at a rate lower than that at which the laboratory charges the federal government directly, and then billing the patient (and the federal insurance program) at a substantially higher rate. Executives of a national pathology laboratory were recently prosecuted for offering highvolume laboratory tests to urologists below cost in return for preferentially using their company to process prostate biopsies. Provision of free drug samples to physicians, some of whom then charge patients for the free medication, was an illegal marketing strategy of some pharmaceutical companies. Use of this tactic by TAP Pharmaceuticals (Lake Forest, IL) when marketing their gonadotropin-releasing hormone agonist leuprolide (Lupron ${ }^{\circledR}$ ) led to another federal prosecution, of the pharmaceutical company and the physicians involved in the scheme.

Traditionally, management of conflicts of interest has been a voluntary process left to the individual physician, with ethical guidance provided by medical societies. Disclosure is a cornerstone; physicians who own an interest in a brachytherapy center, for instance, should disclose that interest when counseling prostate cancer patients about alternative forms of therapy.

Increasingly, however, as the cases cited above demonstrate, the law is being invoked to regulate questionable practices. In the US, anti-kickback and false claim statutes are being utilized in an effort to stamp out certain practices, many of which are currently endemic in clinical settings. That such practices are 'common' in the healthcare industry is an untenable defense. The onus is now on physicians to be aware of their obligations under the law and the serious penalties that can be imposed for breaking those obligations. Medical education-during training and afterwards-should be broadened to include marketing strategies used by commercial ventures as well as other legal issues and ethical obligations of physicians, reinforcing the ideal that responsibility to the patient is paramount in our profession. 